\title{
Implementation of Health-Related Social Needs Screening at Michigan Health Centers: A Qualitative Study
}

\author{
Margaret Greenwood-Ericksen, \\ $M D, M S c^{1}$ \\ Melissa DeJonckbeere, $\mathrm{PbD}^{2,3}$ \\ Faiyaz Syed, $M D^{4}$ \\ Nasbia Choudbury, MPH \\ Alicia J. Coben, $M D, M S c^{2,6,7}$ \\ Renuka Tipirneni, MD, MSc $\mathrm{C}^{3,8}$ \\ 'Department of Emergency Medicine, \\ University of New Mexico, Albuquerque, \\ New Mexico \\ ${ }^{2}$ Department of Family Medicine, Univer- \\ sity of Michigan, Ann Arbor, Michigan \\ ${ }^{3}$ Institute for Healthcare Policy \& Innova- \\ tion, University of Michigan, Ann Arbor, \\ Michigan \\ ${ }^{4}$ Michigan Primary Care Association, \\ Lansing, Michigan \\ ${ }^{5} \mathrm{MyC}$ Care Health Center, Center Line, \\ Michigan \\ ${ }^{6}$ Center of Innovation in Long Term \\ Services and Supports for Vulnerable Popu- \\ lations, Providence VA Medical Center, \\ Providence, Rhode Island \\ ${ }^{7}$ Departments of Family Medicine \\ and Health Services, Policy, and Practice, \\ Brown University, Providence, Rhode Island \\ ${ }^{8}$ Department of Internal Medicine, Univer- \\ sity of Michigan, Ann Arbor, Michigan
}

$8 h_{1}$

\section{MORE ONLINE}

AC Annals Journal Club selection, see inside back cover or https://www. AnnFamMed.org/site/AJC/.

Conflicts of interest: R.T. supported by Ko8 Clinical Scientist Development Award from National Institute on Aging (Ko8AG056591). All other authors report no conflicts of interest.

\section{CORRESPONDING AUTHOR}

Margaret Greenwood-Ericksen

Dept of Emergency Medicine

University of New Mexico

1 Camino de Salud

Albuquerque, NM 87102

mgreenwoodericksen@salud.unm.edu

\begin{abstract}
PURPOSE Federally qualified health centers (FQHCs) are leaders in screening for and addressing patient's health-related social needs but variation exists in screening practices. This variation is relatively unexplored, particularly the influences of organizational and state policies. We employed a qualitative descriptive approach to study social needs screening practices at Michigan FQHCs to characterize screening processes and identify drivers of variation in screening implementation.
\end{abstract}

METHODS Site visits and semistructured interviews were conducted from October 2016 through March 2017, to explore implementation of social needs screening in clinical practice. Five $\mathrm{FQHCs}$ were selected through maximum variation sampling. Within each site, snowball sampling identified care team members highly knowledgeable about social needs screening. We conducted 4 to 5 interviews per site. Transcripts were analyzed using a thematic approach.

RESULTS We interviewed 23 participants from 5 sites; these sites varied by geography, age distribution, and race/ethnicity. We identified 4 themes: (1) statewide initiatives and local leadership drove variation in screening practices; (2) as community health workers (CHW/s) played an integral role in identifying patients' needs, their roles often shifted from that of screener to implementer; (3) social needs screening data was variably integrated into electronic health records and infrequently used for population health management; and (4) sites experienced barriers to social needs screening that limited the perceived impact and sustainability.

CONCLUSIONS FQHCs placed value on the role of CHWs, on sustainable initiatives, and on funding to support continued social needs screening in primary care settings.

Ann Fam Med 2021;19:310-317. https://doi.org/10.1370/afm.2690.

\section{INTRODUCTION}

$\Lambda$ ddressing patients' health-related social needs is integral to patient care, ${ }^{1-6}$ and several state and national agencies incentivize social needs screening innovations. ${ }^{7,8}$ Incentives include national initiatives to establish core social needs measures/screening domains (eg, housing, food insecurity) and to incorporate standardized screening tools into electronic health records. ${ }^{2,6,9,10}$ Although there is broad consensus on the importance of addressing social needs, optimal approaches to screening are unknown ${ }^{2,3}$ but important to advance community health.

Federally qualified health centers (FQHCs) increasingly emphasize health-related social needs screening. ${ }^{11,12}$ Michigan FQHC screening practices are robust, aligning with core screening domains in national initiatives, but they vary in practice. ${ }^{12}$ This variation is under explored, potentially influenced by geography, organizational factors, grants, state efforts, and community health worker (CHW) programs. ${ }^{13,14}$ Short-term grant funding and varying state requirements may limit sustainability and alignment of some initiatives. This study followed implementation of 2 statewide programs (Linkages and Pathways) in Michigan (Supplemental 
Appendix 1, available at https://www.AnnFamMed. org/content/19/4/310/supp1/DC1/), and was conducted concurrently with a State Innovation Model focused on community health and increasing emphasis on $\mathrm{CHW}$ licensure, practice, and professionalism through the establishment of the Michigan Community Health Worker Alliance. ${ }^{15}$ In this study, we conducted inperson qualitative interviews at Michigan FQHCs to examine how screening approaches varied with these statewide programs and structural factors.

\section{METHODS}

\section{Study Design}

This qualitative study exploring variation in social needs screening practices used by Michigan FQHCs was part of a larger mixed methods study with 2 phases (Figure 1) designed to identify the drivers of social needs screening variations to order to improve alignment of screening efforts. The quantitative ${ }^{12}$ and exploratory qualitative findings from phase 1 informed the design (eg, sampling strategy, interview guide) of this phase 2 qualitative study. ${ }^{16}$ Phase 1 data was collected from November 2015 through August 2016 and Phase 2 data was collected from October 2016 through March 2017. Both phases were conducted in partnership with the Michigan Primary Care Association (MPCA), the statewide organization of FQHCs.

\section{Sampling and Recruitment}

Phase 1 indicated alignment in core screening domains across FQHCs ${ }^{12}$ but the exploratory focus group (unpublished) revealed variation in perspectives on screening practices, particularly for urban vs rural settings. Therefore, our phase 2 sampling plan was stratified by geographic diversity and deployed with maximum variation ${ }^{17}$ based on the population served and programmatic involvement. Recruitment occurred in partnership with MPCA, who emailed all 23 FQHCs from phase 1 . The first 5 sites that agreed to participate met the requirements of the sampling frame. Thematic saturation was reached at the culmination of interviews and thus we did not pursue additional recruitment.

Within each site, we used snowball sampling ${ }^{18}$ to identify care team members across roles who were highly knowledgeable about social needs screening. Based on the phase 1 exploratory focus groups, we developed an a priori framework for phase 2 sampling with roles for a screener (completing the screening tool with the patient), implementer (linking patient to needed resources), and administrator (leading dayto-day operations and screening practices). To ensure diversity of perspectives, we completed 4 to 5 interviews per site across these team member roles.

\section{Data Collection}

Semi-structured interviews were guided by literature and screening practices identified in phase 1 (see Supplemental Appendix 2, available at https://www. AnnFamMed.org/content/19/4/310/suppl/DC1/, for a Screener Interview Guide). One-on-one interviews were conducted during site visits by M.G-E., a physician trained in qualitative research and interviewing techniques, and overseen by a qualitative methodologist (M.D.). Interviewees, including leadership and staff, agreed to participate during work hours. Interviews were audio recorded and transcribed with identifying details removed. Transcripts were uploaded

\section{Figure 1. Components of multi-phase mixed methods study.}

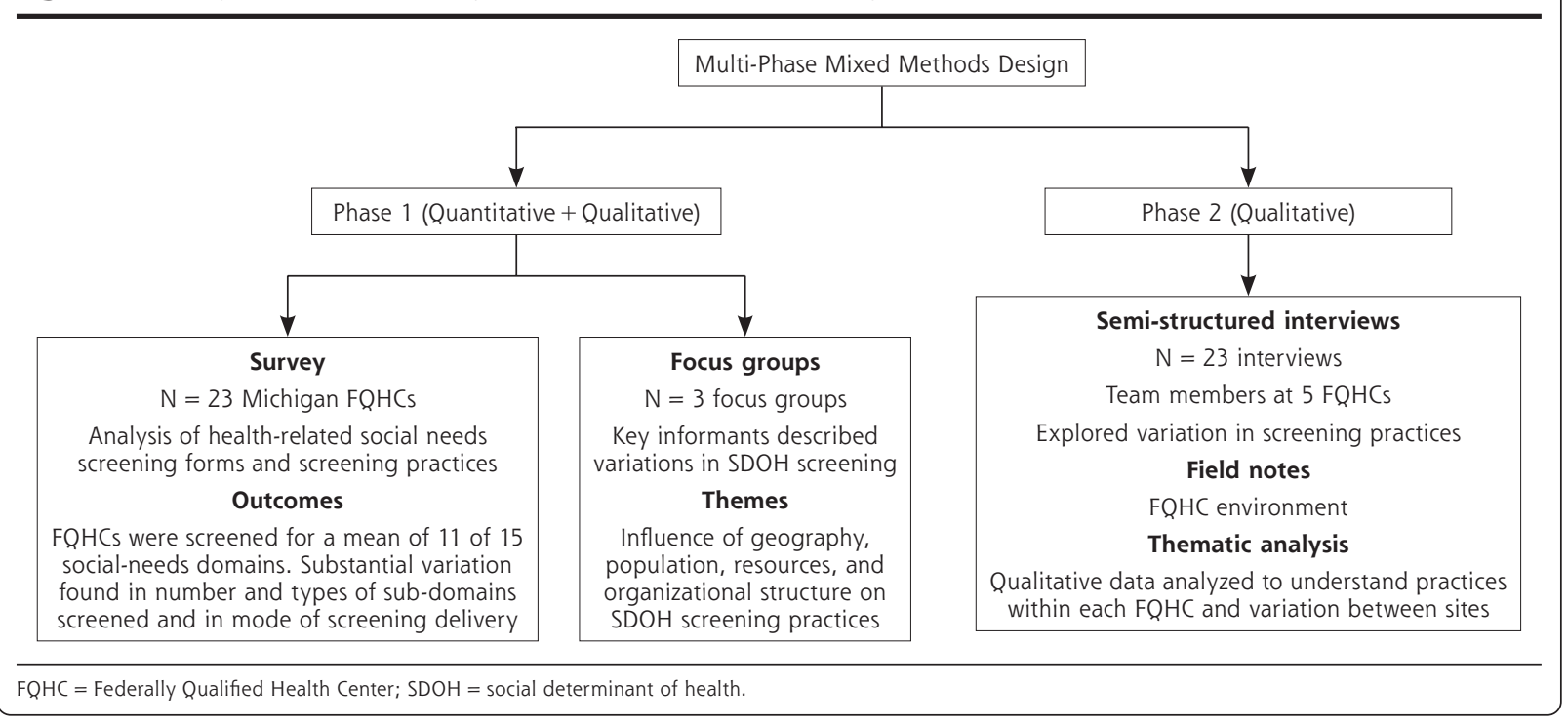


Table 1. Characteristics of Study Sites and Participants

\begin{tabular}{|c|c|c|c|c|c|c|}
\hline \multirow[b]{2}{*}{ Site } & \multicolumn{4}{|c|}{ Site Characteristics $(\mathrm{N}=5)$} & \multicolumn{2}{|c|}{ Participant Roles ( $N=23$ ) } \\
\hline & $\begin{array}{l}\text { Geographic } \\
\text { Setting }\end{array}$ & $\begin{array}{l}\text { Payer Type } \\
\text { Serving } \\
\text { Population }\end{array}$ & $\begin{array}{l}\text { Dominant } \\
\text { Population Served }\end{array}$ & $\begin{array}{c}\text { Participation in State } \\
\text { Demonstration Program }\end{array}$ & $\begin{array}{l}\text { Administrators, } \\
\text { No. }\end{array}$ & $\begin{array}{l}\text { Screenersl } \\
\text { Implementers, } \\
\text { No. }\end{array}$ \\
\hline 1 & Rural & Mix of insurance & White & Yes (Linkages, SIM) & 1 & 3 \\
\hline 2 & Rural & Medicaid & $\begin{array}{l}\text { White, young families, } \\
\text { older adults }\end{array}$ & Yes (Linkages) & 1 & 4 \\
\hline 3 & Urban & Medicaid & $\begin{array}{l}\text { Black, Hispanic, undoc- } \\
\text { umented immigrants }\end{array}$ & No (Diabetes grant) & 1 & 5 \\
\hline 4 & Rural/suburban & Mix of insurance & Black, White & Yes (Linkages) & 1 & 2 \\
\hline 5 & Urban/suburban & Medicaid & Black & Yes (Pathways, Linkages) & 1 & 4 \\
\hline \multicolumn{7}{|c|}{ SIM = State Innovation Model. } \\
\hline \multicolumn{7}{|c|}{$\begin{array}{l}\text { a Several state programs promoting social needs screening were implemented during the study period, including the Linking Clinical Care with Community Supports } \\
\text { (Linkages) project, the Michigan Pathways to Better Health (Pathways), and the State Innovation Model (SIM), as described under "Context and Setting" in Supplemen- } \\
\text { tal Appendix 1, available at https://www.AnnFamMed.org/content/19/4/xxx/suppl/DC1/. }\end{array}$} \\
\hline
\end{tabular}

into Dedoose (SocioCultural Research Consultants), ${ }_{1}^{19}$ a web-based software for qualitative analysis.

\section{Data Analysis and Interpretation}

Transcripts were analyzed using a descriptive approach. ${ }^{20}$ Four team members (M.G-E., M.D., A.J.C., R.T.) initially reviewed 2 transcripts and independently created a list of codes marking meaningful text. The team compared the lists of codes, combining and reducing codes to develop a codebook. Two team members (M.G-E., M.D.) independently applied these codes to 2 additional transcripts, iteratively refined the codebook, and applied codes to all transcripts. Themes were identified, reviewed, and refined with all team members with supporting selections of representative quotations. Themes were compared within and across participant roles and sites. Our preliminary findings were reviewed with our community partners at MPCA (F.S., N.C.), who added contextual richness based on their discussions and observations of screening within state FQHCs.

\section{Research Quality}

We maintained research integrity ${ }^{8}$ by: (1) building an interprofessional research team, including an emergency physician, family physician, internist, qualitative methodologist, and statewide FQHC leadership ${ }_{i}(2)$ discussing findings with relevant community stakeholders for interpretation; and (3) presenting findings using thick description ${ }^{21}$ and participant quotations.

\section{RESULTS}

A total of 23 participants from 5 federally qualified health centers took part in the study, including
5 administrators, 8 implementers, and 10 screeners. Interviews lasted an average of 48 minutes. Table 1 shows the characteristics of the study sites and participants. Screeners and implementers were combined as we found significantly more overlap between these roles than we initially theorized in our role conceptualization. Each site included interviews with a medical director, a community health worker, and a registered nurse case manager. Table 2 describes screening practices that varied between sites, including identification of patients, screening method, screening tool, and resource linkage. Through descriptive analysis, we identified 4 themes related to variation in social needs screening across the 5 sites (Supplemental Table 1, available at https://www.AnnFamMed.org/ content/19/4/310/suppl/DC1/).

\section{Theme 1: Variation in Screening Practices}

Theme 1 identified statewide initiatives and local leadership as drivers of variation in screening practices.

\section{Selection of Patient Population}

Participants explained that programmatic requirements and internal leadership decisions influenced which patient populations were screened. Some sites focused screening efforts on new patients or chose a specific group based on perceived need or programmatic funding requirements (eg, specific demographics or medical conditions). At site 3, CHWs who conducted screenings were directly funded through a diabetes-specific program and only patients enrolled in that program received social needs screening. At this site, CHWs expressed concerns about the narrow scope and a desire to expand screening efforts to additional patient populations: 
"We only screen the people that we talk to and who participate in the program. If you compare to the number of people that are here and have diabetes and other chronic conditions, I mean, it's nothing!" (screener/implementer, site 3).

\section{Selection of Screening Tools}

Programmatic requirements influenced standardization of screening tools; no sites described using available evidence to guide selection of screening tools. One program required the use of the PRAPARE screening tool, ${ }^{10}$ which standardized processes between FQHCs:

"When I went to CHW training to get certified, that's where I learned about the PRAPARE [screening tool] and we just kept using it even after we got out of the [state] program" (screener/implementer, site 4).
The administrators, screeners, and implementers spoke to the merits of a standardized screening approach to avoid missing important needs and to standardize comparisons across sub-groups. All FQHCs, however, indicated that they tailored screenings for their specific patient populations.

\section{Screening Delivery Methods}

Variation was identified in both mode of delivery and roles of care team members. Initial screening methods ranged from a pre-visit telephone call by a CHW (site 2) to an in-person assessment with a CHW (sites 3, $4,5)$. Site 1 had front desk or medical assistant staff perform the initial screen instead of CHWs. This latter approach, of front desk/medical assistant screeners,

Table 2. Comparison of Screening Practices Across FQHC Sites: Key Findings From Theme 1

\begin{tabular}{|c|c|c|c|c|c|}
\hline Subthemes & Site 1 & Site 2 & Site 3 & Site 4 & Site 5 \\
\hline $\begin{array}{l}\text { Identification } \\
\text { of patients }\end{array}$ & $\begin{array}{l}\text { Targeted rollout } \\
\text { Started with Medicaid } \\
\text { patients as a pilot } \\
\text { program } \\
\text { Layers of screen- } \\
\text { ing-in which all } \\
\text { care team members } \\
\text { were encouraged } \\
\text { to perform social } \\
\text { needs screening with } \\
\text { patients at any point } \\
\text { of contact. }\end{array}$ & $\begin{array}{l}\text { All patients, starting } \\
\text { with new patient } \\
\text { appointment } \\
\text { Screening conducted } \\
\text { by telephone with } \\
\text { CHW, in person by } \\
\text { case/care manage- } \\
\text { ment RNs, and } \\
\text { medical providers }\end{array}$ & $\begin{array}{l}\text { Targeted rollout } \\
\text { Started with patients } \\
\text { enrolled in specific } \\
\text { programs at their } \\
\text { first new patient } \\
\text { appointment } \\
\text { Sometimes medical } \\
\text { team would ask } \\
\text { for resources for } \\
\text { patients not part of } \\
\text { targeted rollout }\end{array}$ & $\begin{array}{l}\text { All patients, } \\
\text { starting with } \\
\text { new patient } \\
\text { appointment }\end{array}$ & $\begin{array}{l}\text { Targeted rollout } \\
\text { Started with patients aged } \\
18 \text { years and older, those } \\
\text { referred by physicians, } \\
\text { and patients with high ED } \\
\text { utilization } \\
\text { Expanded to behavioral } \\
\text { health, prenatal visits } \\
\text { Front desk distributed screen- } \\
\text { ing to all new patients and } \\
\text { patients with health care } \\
\text { maintenance exams }\end{array}$ \\
\hline $\begin{array}{l}\text { Team mem- } \\
\text { bers per- } \\
\text { forming } \\
\text { screening }\end{array}$ & $\begin{array}{l}\text { Front desk at initial new } \\
\text { patient appointment } \\
\text { CHW, case/care manag- } \\
\text { ers as needed } \\
\text { Layers of screening }\end{array}$ & $\begin{array}{l}\text { CHW by telephone } \\
\text { before first new } \\
\text { patient appointment } \\
\text { Case/care managers, } \\
\text { mental health refer- } \\
\text { ral as needed } \\
\text { Layers of screening }\end{array}$ & $\begin{array}{l}\text { CHW } \\
\text { Case/care managers } \\
\text { as needed }\end{array}$ & $\begin{array}{l}\text { MAs, CHWs } \\
\text { Layers of } \\
\text { screening }\end{array}$ & $\begin{array}{l}\text { CWH initially } \\
\text { Added MAs and case/care } \\
\text { managers as screeners } \\
\text { Layers of screening }\end{array}$ \\
\hline $\begin{array}{l}\text { Screening } \\
\text { approach }\end{array}$ & Standardized & $\begin{array}{l}\text { Standardized } \\
\text { Tailored to popula- } \\
\text { tion (eg, younger, } \\
\text { older) }\end{array}$ & $\begin{array}{l}\text { Standardized } \\
\text { Adaptations for spe- } \\
\text { cific communities } \\
\text { (eg, Black, Hispanic) }\end{array}$ & Standardized & Standardized \\
\hline $\begin{array}{l}\text { Screening } \\
\text { tool }\end{array}$ & $\begin{array}{l}\text { PRAPARE initially, then } \\
\text { moved to screening } \\
\text { tool from the North- } \\
\text { ern Physicians Organi- } \\
\text { zation (as part of SIM) }\end{array}$ & PRAPARE & Internally developed & $\begin{array}{l}\text { PRAPARE } \\
\text { (internally } \\
\text { customized) }\end{array}$ & PRAPARE \\
\hline $\begin{array}{l}\text { Role linking } \\
\text { patient to } \\
\text { resources }\end{array}$ & $\begin{array}{l}\text { CHW, case/care } \\
\text { manager }\end{array}$ & CHW & CHW & CHW & CHW \\
\hline
\end{tabular}


was being considered by sites 4 and 5, both of which discussed future plans to use a tablet-based screening tool, which syncs directly with the electronic health record (EHR). At site 5, an administrator hypothesized that patients "may be more apt to answer" screening questions administered using a personal electronic device given the increased privacy afforded by self-administration.

Some sites (sites 1, 2, 4, 5) explicitly stated that while they had standard formal screening processes, they also deployed "layers of screening" in which all care team members could screen patients at any point of contact. If social needs were identified, patients were referred for additional formal screening. One participant explained the rationale:

"I think anybody can do it, as long as they have the understanding of what we are trying to do. I think you have to understand that we are trying to empower these people... that's what we are trying to do" (screener/implementor, site 5).

\section{Theme 2: Shift in CHW Roles}

Theme 2 revealed that as CHWs played an integral role in identifying patients' needs, their roles often shifted from that of screener to implementer.

\section{Value of CHWs}

The value of CHWs was clearly expressed across all sites. Participants reported that having CHWs at FQHCs had changed the culture and practice related to addressing patients' social needs:

"...when I first listened to the conversation [implementing social needs screening by $\mathrm{CHWs}]$... How are we going to do that? I don't think we could ever pull it off. I don't think we have time... [social needs screening] changed our dynamic so much. ... And just looking at health care the way it used to be, there was never time for those things and now, we have kind of evolved it the other way, that we put the preventative measures in and then, outcomes come... We can do it. And it's kind of like the village" (implementor, site 4).

Participants noted that patients seem more likely to open up to $\mathrm{CHWs}$ than physicians and believed that physicians might not have time to provide sufficient patient education. Some CHWs wanted to help educate patients about disease self-management but had limited time, given more pressing issues: "We are always putting out fires... somebody got their electricity shut off this morning" (screener/implementor, site 5).

Several sites indicated that their CHWs were "too valuable" to be screeners and were more effective at connecting patients to resources to address social needs. As a result, the role of CHWs evolved after screening was initiated at some sites.

\section{Theme 3: Variable Integration of Screening Data}

Theme 3 discovered social needs screening data was variably integrated into EHRs and infrequently used for population health management.

\section{Electronic Health Records}

All sites had plans to directly embed screening tools (and associated data) into EHRs. Two sites $(1,4)$ reported moving toward a technology with a digital pen that captures patients' handwritten data and incorporates it directly into the EHR:

"We are looking at upgrading to what they call NextPen or-it is an iPad but when the patient comes in, they can just do that screening confidentially, click it and it will go right into their medical record and we will have access to that" (administrator, site 1).

Sites using paper screening tools at the time of the study had plans to integrate this into their EHRs in the near future. Even within sites, however, there was inconsistency in data entry.

"I feel the electronic health record is great but there is also cons to it... And what I have found as administrator or doing the data is that not everyone is doing it the same way" (administrator, site 3).

\section{Population Health Management}

At the time of data collection, sites were not focused on using social needs data for population health management. When asked about using collected data to drive population health, one administrator explained: "we have so much data sometimes, we don't know what to do with it" (administrator, site 5). Another responded: "I don't think that is necessary part of our structure, to tell you the truth" (administrator, site 2). Participants described using data to identify gaps for individual patients, rather than tracking data trends or social needs across the population.

\section{Theme 4: Barriers Limited Impact}

Theme 4 showed sites experienced barriers to social needs screening that limited the perceived impact and sustainability.

\section{Resource and Staff Availability}

Concerns about limited resources, staff availability, and capacity of the community to address social needs were mentioned across all sites, though most notably among rural FQHCs. One Administrator noted:

\footnotetext{
"...what we chose to do is being very....methodical, only because we could have said every person who walks through the door is screened. And then, we would have,
} 
you know, 15,000 screened, but what did we do for them?" (administrator, site 5).

Participants also expressed concerns about staff availability and the time it takes to assist patients with social needs. A CHW noted this work is time-consuming:

"Usually, if the patient is comfortable with you, should take about 20 minutes. But, there have been cases where you take an hour, hour and half, because they don't want to answer so, you have to ask the same questions in about three different ways" (screener, site 3).

In addition, participants noted that $\mathrm{CHWs}$ were often pulled from performing social needs screening to attend to other tasks. Participants from rural sites in particular (sites 1,2) described feeling stretched thin, resulting in the sense that "we are one step away from chaos" (implementor, site 1). CHWs reported anxiety and one explained:

"If we are going to do integration, we need to be in there, in the clinic all day because the minute that I leave to go to a different desk, a different spot, I miss that opportunity with the provider because the providers don't have time to come, run and grab us and bring us back and do-so, it's just being there, consistent, and meeting with the patient" (screener, site 2).

\section{Sustainability}

Participants described current payment structures for CHW funding as a barrier to sustainability in social needs screening and clinic operations. Administrators indicated the need for direct CHW reimbursement, as they are currently non-budgeted positions. One participant described:

"... I worry about continued funding because no enabling services-so that's your community health workers, your care managers, case managers... We have patients that live off the grid, pay out of pocket. They still need the services and we want to be able to offer those services... We are fortunate that we do have the monies that we are getting from the state for the State Innovation Model to work on all of this" (administrator, site \#1).

\section{DISCUSSION}

In this qualitative study of social needs screening at Michigan FQHCs, screening practices were influenced by statewide initiatives promoting and funding social needs screening, the growing importance of CHWs in linkage to services, resource constraints within FQHCs and communities, and local leadership decisions. At the time of the study, variation existed in the type of screening instruments used and integration into EHRs.
Population health management was not a strong focus. While participants described barriers to the potential impact and sustainability, FQHCs are deeply invested in social needs screening and desire state and federal entities to support such efforts.

Our findings provide important insights into the rapidly evolving landscape of social needs screening. Two statewide programs (Linkages and Pathways) used the PRAPARE screening too ${ }^{10}$ but each community region in the State Innovation Model ${ }^{22}$ developed separate tools with varied content and administration. As each FQHC responded to funding opportunities and practice-driven initiatives, FQHCs emphasized different areas of focus and activities. National initiatives $^{23}$ now promote broader social needs screening, but few ambulatory care centers have developed systematic screening approaches ${ }^{11,24}$ and there remains a lack of standardized workflows and screening tools. ${ }^{25}$ The MPCA now encourages all Michigan FQHCs to use the PRAPARE screening tool. ${ }^{26}$ While there are aspects of screening that may benefit from standardization (eg, the use of core domains and integration into EHRs), our findings indicate that screening variation was often driven by a perceived need to tailor screening practices to local communities' needs rather than by emerging evidence on screening. ${ }^{27}$ Some sites reduced the number of questions in the screening tool to focus on those salient to their community (eg, healthy food access), avoided asking about needs for which there were scarce resources, and modified the wording of the questions for specific populations. A key question is whether there is a point at which standardization results in reduced efficacy of screening by failing to consider the local context, population, and patient perspective. ${ }^{28-31}$ Our study is hypothesis generating in this regard, particularly as many health care systems are moving toward systematic screening and referral practices. Future work may include applying an implementation science framework to better understand the tension in real-world deployment of screening practices and exploring the important perspectives of patients and their perceived satisfaction with social needs screening methods. ${ }^{30,31}$

Integration of screening processes and data into EHRs coupled with population health management efforts are important next steps in identifying and addressing patient's health-related social needs. ${ }^{2,6}$ Electronic health record vendors are developing products for collection and use of social needs screening data, but without national standards, vendor decisions may drive national policies. ${ }^{32,33}$ This is potentially concerning, as vendors' goals are largely profit driven rather than health focused. Consistency of screening documentation varies widely even after embedding 
screening tools into EHRs, suggesting other barriers. ${ }^{34}$ Though population health was not a focus at the time of this study, many Michigan FQHCs have since implemented a population health management tool ${ }^{35}$ to aggregate data across several FQHCs, ${ }^{26}$ partly driven by the National Association of Community Health Centers. This organization's goal is for all health centers to implement the PRAPARE screening tool and centralize data reporting for population health management by building provider scorecards, dashboards, registries, and risk scores related to social needs.

Federally qualified health centers sustain their social needs programs through funding streams including patient revenue, time-limited grants, and demonstration projects. ${ }^{13}$ Some of these directly fund screening efforts while others fund key positions needed for screening (eg, CHWs, care navigators, case managers). Stakeholders have called for more sustainable funding sources such as encouraging FQHCs to rely more on patient revenue, adjusting payments for patients' social risk, allowing flexibility of covered services, or allowing fee-for-service billing for CHWs and other team members that connect patients to and deliver social services. ${ }^{36-38}$ In particular, literature supports the value of CHWs as uniquely positioned to serve as screeners and implementers, ${ }^{39,40}$ which is consistent with our findings. Supporting professionalization and licensure of CHWs through direct billing for their services would serve to advance health care efforts to improve patients' health-related social needs.

\section{Limitations}

Study limitations include self-reported results limited to the perspectives of FQHC staff. Qualitative methods, however, are ideal for assessing the process of implementation and perspectives of team members. We conducted site visits and interviews in a single state, however, the study context was a large, geographically diverse state with FQHCs serving diverse patient populations. Sampling was done purposively to achieve maximum variation in perspectives and experiences across geographic settings. While our study describes important findings from a period of numerous state demonstration programs, screening practices continued to evolve. To address this limitation, we continued close contact with the MPCA between the conclusion of the study and publication to assure up-to-date knowledge on current statewide screening efforts.

\section{CONCLUSION}

In our study, statewide programmatic requirements and internal leadership decisions drove variation in social needs screening practices. Community health workers were universally valued, serving as both screeners and implementers of social needs screening and community linkages, and FQHCs reported a need for sustainable funding to support social needs screening in primary care settings.

To read or post commentaries in response to this article, go to https://www.AnnFamMed.org/content/19/4/310/tab-e-letters.

Key words: community health centers; community health workers; primary health care; social determinants of health

Submitted May 21, 2020; submitted, revised, November 18, 2020; accepted December 3, 2020.

Funding support: This study was supported by a grant from the Blue Cross Blue Shield Foundation of Michigan (002464.PIRAP) and funding from the Michigan Institute for Clinical \& Health Research (MICHR) Pilot Grant Program (UL1TR00220). R.T. supported by K08 Clinical Scientist Development Award from National Institute on Aging (K08AG056591). The funding agencies had no part in the study design, data collection, analysis, interpretation of the finding or decision to submit the manuscript for publication.

Acknowledgments: The authors would like to thank and acknowledge the participating health centers and our MPCA collaborators.

Supplemental materials: Available at https://www.AnnFamMed. org/content/19/4/310/suppl/DC1/.

\section{References}

1. Social determinants of health. World Health Organization. Accessed Sep 8, 2020. https://www.who.int/social_determinants/sdh_ definition/en/

2. IOM (Institute of Medicine). Capturing Social and Behavioral Domains and Measures in Electronic Health Records: Phase 2. The National Academies Press; 2014. https://www.ncbi.nlm.nih.gov/books/NBK268995/

3. National Academies of Sciences, Engineering, and Medicine. Investing in Interventions That Address Non-Medical, Health-Related Social Needs: Proceedings of a Workshop. The National Academies Press; 2019. https://doi.org/10.17226/25544

4. National Academies of Sciences, Engineering, and Medicine. Integrating Social Care into the Delivery of Health Care: Moving Upstream to Improve the Nation's Health. The National Academies Press; 2019. https://doi.org/10.17226/25467

5. National Quality Forum. National quality forum leads national call to address social determinants of health through quality and payment innovation. Published Oct 24, 2019. Accessed Aug 30, 2020. https://www.qualityforum.org/News_And_Resources/Press_ Releases/2019/National_Quality_Forum_Leads_National_Call_to_ Address_Social_Determinants_of_Health__through_Quality_and_ Payment_Innovation.aspx

6. IOM (Institute of Medicine). Capturing Social and Behavioral Domains and Measures in Electronic Health Records: Phase 1. The National Academies Press; 2014. https://www.ncbi.nlm.nih.gov/books/NBK195994/

7. Alley DE, Asomugha CN, Conway PH, Sanghavi DM. Accountable health communities-addressing social needs through Medicare and Medicaid. N Engl J Med. 2016;374(1):8-11. 10.1056/NEJM p1512532.

8. Health and Human Services. The root of the problem: america's social determinants of health. HHS.gov. Published Nov 14, 2018 Accessed Aug 13, 2020. https://www.hhs.gov/about/leadership/ secretary/speeches/2018-speeches/the-root-of-the-problemamericas-social-determinants-of-health.html

9. Research on Integrating Social \& Medical Care. The gravity project. Accessed Aug 28, 2020. https://sirenetwork.ucsf.edu/TheGravity Project 
10. National Association for Community Health Centers. PRAPARE. Accessed Aug 20, 2020. https://www.nachc.org/research-and-data/ prapare/

11. Fraze TK, Brewster AL, Lewis VA, Beidler LB, Murray GF, Colla CH. Prevalence of screening for food insecurity, housing instability, utility needs, transportation needs, and interpersonal violence by us physician practices and hospitals. JAMA Netw Open. 2019;2(9): e1911514-e1911514. 10.1001/jamanetworkopen.2019.11514.

12. Byhoff E, Cohen AJ, Hamati MC, Tatko J, Davis MM, Tipirneni R. Screening for social determinants of health in Michigan health centers. J Am Board Fam Med. 2017;30(4):418-427. 10.3122/jabfm. 2017.04.170079.

13. Gottlieb L. Razon, Na'amah, Aboelata, Noah. How Do Community Health Centers Pay for Social Care Programs? Social Interventions Research \& Evaluation Network (SIREN); 2019.

14. Gottlieb L, Razon N, Aboelata N. How Do Safety Net Clinics Pay for Social Care Programs? Social Interventions Research \& Evaluation Network; 2019. https://sirenetwork.ucsf.edu/tools-resources/ resources/how-do-safety-net-clinics-pay-social-care-programs

15. MiCHWA. Our History. Accessed Aug 18, 2020. https://www. michwa.org/our-historyl

16. Creswell JW, Clark VLP. Designing and Conducting Mixed Methods Research. SAGE Publications; 2017.

17. Palinkas LA, Horwitz SM, Green CA, Wisdom JP, Duan N, Hoagwood K. Purposeful sampling for qualitative data collection and analysis in mixed method implementation research. Adm Policy Ment Health. 2015;42(5):533-544. 10.1007/s10488-013-0528-y.

18. Patton MQ. Qualitative Evaluation and Research Methods, 2nd Ed. Sage Publications, Inc; 1990.

19. Dedoose. Accessed Feb 20, 2020. https://www.dedoose.com/ ?gclid=EAlalQobChMluryQx9Lg5wIVBB-tBh0qMQgOEAAYASAAEg Ln7_D_BwE

20. Sandelowski M. Whatever happened to qualitative description? Res Nurs Health. 2000;23(4):334-340.

21. Lincoln Y, Guba E. Naturalistic Inquiry. SAGE; 1985.

22. Michigan Department of Health and Human Services. State innovation model. Accessed Aug 18, 2020. https://www.michigan.gov/ mdhhs/0,5885,7-339-71551_64491-,00.html

23. Andermann A. Screening for social determinants of health in clinical care: moving from the margins to the mainstream. Public Health Rev. 2018;39:19. 10.1186/s40985-018-0094-7.

24. Chung EK, Siegel BS, Garg A, et al. Screening for social determinants of health among children and families living in poverty: a guide for clinicians. Curr Probl Pediatr Adolesc Health Care. 2016; 46(5):135-153. 10.1016/j.cppeds.2016.02.004.

25. Olson DP, Oldfield BJ, Morales Navarro S. Standardizing social determinants of health assessments. Health Affairs blog. Mar 18, 2019. https://www.healthaffairs.org/do/10.1377/hblog20190311. 823116/full/

26. Michigan Primary Care Association. Personal communication among authors (M.G.E., M.D., A.J.C., R.T., F.S., N.C.). Feb 17, 2020.
27. Byhoff E, Garg A, Pellicer M, et al. Provider and staff feedback on screening for social and behavioral determinants of health for pediatric patients. J Am Board Fam Med. 2019;32(3):297-306. 10.3122I jabfm.2019.03.180276.

28. Rogers AJ, Hamity C, Sharp AL, Jackson AH, Schickedanz AB. patients' attitudes and perceptions regarding social needs screening and navigation: multi-site survey in a large integrated health system. J Gen Intern Med. 2020;35(5):1389-1395. 10.1007/ s11606-019-05588-1.

29. Hsu C, Cruz S, Placzek H, et al. Patient perspectives on addressing social needs in primary care using a screening and resource referral intervention. J Gen Intern Med. 2020;35(2):481-489. 10.1007/ s11606-019-05397-6.

30. De Marchis EH, Hessler D, Fichtenberg C, et al. Part I: a quantitative study of social risk screening acceptability in patients and caregivers. Am J Prev Med. 2019;57(6)(Suppl 1):S25-S37. 10.1016/j.amepre. 2019.07.010.

31. Byhoff E, De Marchis EH, Hessler D, et al. Part II: a qualitative study of social risk screening acceptability in patients and caregivers. Am J Prev Med. 2019;57(6)(Suppl 1):S38-S46. 10.1016/j.amepre. 2019.07.016.

32. Freij M, Dullabh P, Lewis S, Smith SR, Hovey L, Dhopeshwarkar R. Incorporating social determinants of health in electronic health records: qualitative study of current practices among top vendors. JMIR Med Inform. 2019;7(2):e13849. 10.2196/13849.

33. Cantor MN, Thorpe L. Integrating data on social determinants of health into electronic health records. Health Aff (Millwood). 2018; 37(4):585-590. 10.1377/hlthaff.2017.1252.

34. Cottrell EK, Dambrun K, Cowburn S, et al. Variation in electronic health record documentation of social determinants of health across a national network of community health centers. Am J Prev Med. 2019;57(6)(Suppl 1):S65-S73. 10.1016/j.amepre.2019.07.014.

35. Azara. Accessed Feb 20, 2020. https://azarahealthcare.com/

36. Huffstetler AN, Phillips RL Jr. Payment structures that support social care integration with clinical care: social deprivation indices and novel payment models. Am J Prev Med. 2019;57(6)(Suppl 1):S82S88. 10.1016/j.amepre.2019.07.011.

37. Gottlieb LM, DeSalvo K, Adler NE. Healthcare sector activities to identify and intervene on social risk: an introduction to the American Journal of Preventive Medicine supplement. Am J Prev Med. 2019;57(6)(Suppl 1):S1-S5. 10.1016/j.amepre.2019.07.009.

38. Johnson D, Saavedra $P$, Sun $E$, et al. Community health workers and medicaid managed care in New Mexico. J Community Health. 2012; 37(3):563-571. 10.1007/s10900-011-9484-1.

39. Roman LA, Raffo JE, Meghea Cl. Maternal perceptions of help from home visits by nurse-community health worker teams. Am J Public Health. 2012;102(4):643-645. 10.2105/AJPH.2011.300455.

40. O'Brien MJ, Squires AP, Bixby RA, Larson SC. Role development of community health workers: an examination of selection and training processes in the intervention literature. Am J Prev Med. 2009; 37(6)(Suppl 1):S262-S269. 10.1016/j.amepre.2009.08.011. 